\title{
Correction to: Bioprocess for Solid Waste Management
}

Radhika Deshmukh, Anshuman A. Khardenavis, and Hemant J. Purohit

\section{Correction to:}

Chapter 4 in: H.J. Purohit et al. (eds.), Optimization and Applicability of Bioprocesses, https://doi.org/10.1007/978-981-10-6863-8_4

A list of references in Chapter 4 starting from "Haider MA, Pakshirajan K, Singh A, Chaudhry S (2008)" to the reference "Kurniawan TA, Lo WH, Chan GY (2006)" was incorrectly prefixed with doi: https://doi.org/10.5772/56205. This has now been corrected. 